\title{
Restauración de un libro gravemente deteriorado: Índice de la Librería de la Condesa de Campo de Alange. 1779
}

Javier Tacón Clavaín, Universidad Complutense de Madrid. Biblioteca Histórica "Marqués de Valdecilla"

\section{Resumen}

En el artículo se relata el proceso llevado a cabo para la recuperación de la obra, la cual se encontraba en un estado tal que no permitía su uso debido al grave deterioro biológico ocasionado por un mojado continuado.

En primer lugar se realiza una descripción de la obra, tanto en sus valores intelectuales como materiales, justificando la intervención dada la gran significación que tiene el objeto para el centro depositario. A continuación se detallan los resultados de los análisis previos que sirven para describir el estado de conservación y, en base al valor intrínseco del bien y al resultado de las pruebas, establecer el tratamiento a seguir.

Finalmente se describe el desarrollo del tratamiento, cuya característica principal reside en procurar la mínima intervención, respetando todos los elementos originales de la obra, incluyendo el cosido original ya que el libro fue intervenido sin el desmontaje previo de los cuadernos.

\section{Palabras clave}

Análisis / Universidad Complutense de Madrid. Biblioteca / Centro de Intervención / Conservación / Historia / Instituto Andaluz del Patrimonio Histórico / Intervención / Libros / Patrimonio mueble / 1779 


\section{IDENTIFICACIÓN DE LA OBRA}

\section{Identificación intelectual y valor intrínseco'}

Se trata de un rarisimo inventario de libros de una biblioteca nobiliaria del siglo XVIII, con la particularidad de que la poseedora de la colección era una mujer: Agustina de la Torre, condesa de Campo Alange por matrimonio con Ambrosio José de Negrete. La colección relacionada en el inventario y en suplementos posteriores (BURGALETA; DÍAZ, 2006), cuidadosamente manuscritos, quedó vinculada al mayorazgo, y transmitida a los sucesivos condes, hasta que en 1891 fue adquirida por el estado, que destinó a la Biblioteca Nacional los ejemplares que ésta no poseía. Pero la mayor parte del fondo se encuentra actualmente en la Biblioteca Histórica de la Universidad Complutense de Madrid, procedente de la Biblioteca de San Isidro. El inventario formaba parte de los fondos del archivo particular de la Casa de Campo de Alange y fue donado en 2003 por la actual Condesa-Almudena Salamanca y Suelves- a la Biblioteca Universitaria antes citada, depositaria de buena parte de los registros bibliográficos que contiene².

La descripción de los libros está ordenada por materias y, dentro de cada materia, por orden alfabético de autor. Las materias que figuran son: (a) Historia, (b) Poesia y fábula, (c) Política y crítica, y (d) Miscelánea ${ }^{3}$.

Este inventario posee un alto valor para la entidad depositaria: su contenido es una importante fuente de información para el estudio de una gran colección privada, formada por una destacada bibliófila durante el periodo de la llustración, colección que ingresó en la Universidad a finales del s. XIX y es, por tanto, una de las fuentes de la propia historia que ha configurado el fondo bibliográfico histórico de la Universidad Complutense de Madrid (SANTOS, 2004).

\section{Descripción material}

Cuerpo del libro

Obra manuscrita con tinta ferrogálica sobre papel verjurado J. Honig \& Zoonen. El mismo tipo de tinta se utilizó tanto para la grafía como en la decoración de las letras capitales. Presenta anotaciones y correcciones con grafito.

El libro no se encuentra foliado. Debido a su precario estado de conservación no se pudo documentar previamente el número de hojas ni la disposición de los cuadernos, lo cual fue realizado durante la intervención de consolidación de las hojas, advirtiéndose al final de dicho tratamiento que el cuerpo del libro se compone de 118 hojas en 17 cuadernos.

El volumen presenta numerosas hojas en blanco, particularmente en su parte final, estando sin grafia las 24 últimas hojas.

\section{Encuadernación}

Estructura4. Cuadernos cosidos con hilo blanco a punto seguido sobre 6 nervios de cuerda. Las guardas y hojas de respeto aparecen cosidas como elementos independientes cuya disposición -tanto la anterior como la posterior- era la siguiente: una hoja de respeto con pliegue en escartivana -formando una solapa- envuelve al bifolio de papel pintado que forma la guarda. La solapa de la hoja de respeto, adherida a la contratapa, actúa de refuerzo en la estructura de la encuadernación.

Cabezadas -que sólo conserva una- cosidas en hilos azul y blanco. La estructura no presenta material de enlomado, sólo aplicación de adhesivo. Las tapas son de cartón blanco grueso y su unión con el cuerpo del libro se realizó mediante el pegado de los nervios deshilachados sobre la cara exterior de cada tapa, sin enlazar con ésta mediante encartonado tradicional.

Decoración. En el terreno exclusivamente decorativo de la encuadernación destacan el papel pintado utilizado como guarda y el trabajo decorativo en la piel de la cubierta realizado mediante dos técnicas: pintado y dorado.

Pintado en contracantos en forma de líneas paralelas oblicuas al canto y en las tapas en forma de jaspeado -picado fino- en toda la superficie, formando una composición romboidal con el jaspeado más denso.

Dorado con hilos e hierros de motivos vegetales y geométricos en cantos, planos de las tapas y lomo. En las tapas la composición romboidal se perfila con líneas de oro, incluyendo, en ambas tapas, un óvalo central dorado, presentando en su interior -sólo en el de la tapa anterior- la leyenda campo alhanje manuscrita con tinta.

\section{ESTADO DE CONSERVACIÓN}

\section{Análisis previos}

Fueron realizadas las siguientes pruebas con el fin de recabar información acerca de la condición de los materiales para la determinación de un tratamiento apropiado.

\section{Pruebas sobre el cuerpo del libro}

Determinación de iones $\mathrm{Fe}(\mathrm{II})$ en la tinta. Se utilizaron tiras indicadoras de batofenantrolinas. El resultado de la prueba fue claramente positivo, lo que indica que la tinta presenta actividad oxidativa catalizada por este ión.

Medición del pH del papel. Aprovechando la circunstancia de la presencia de múltiples fragmentos de papel, sin grafía, que no podian ser recolocados en la obra, la medición del pH se realizó en varios de estos fragmentos. Las mediciones se efectuaron con medidor de pH Hanna 8417 y electrodo de contacto HI 1413 previa calibración con soluciones patrón, siguiendo el siguiente método: 


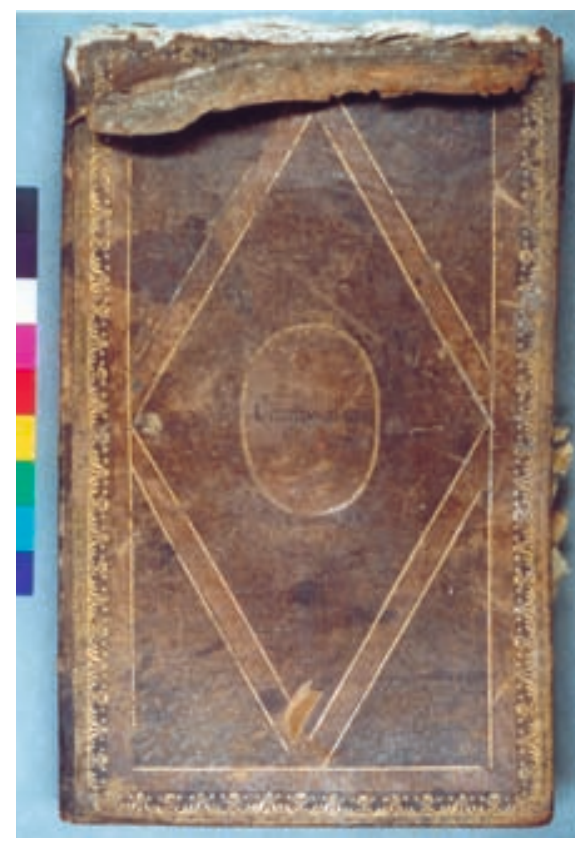

Estado inicial de la cubierta
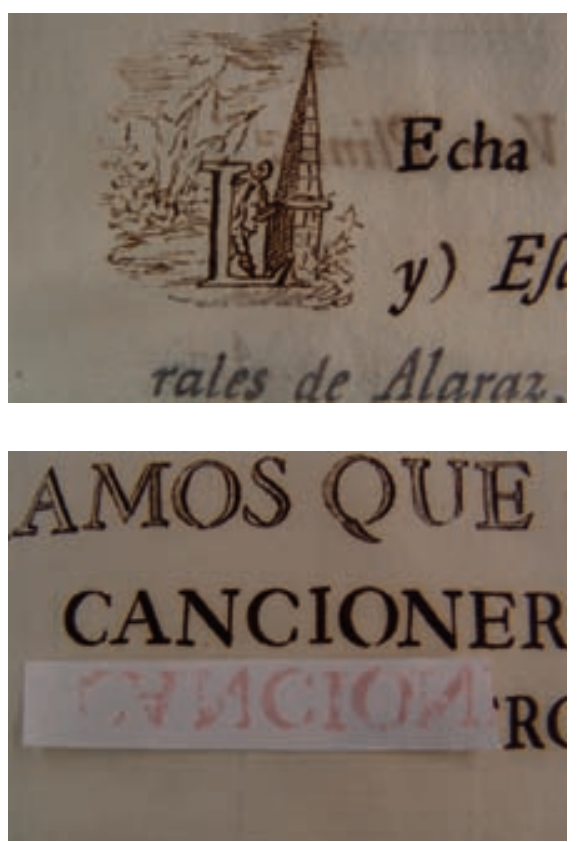

Arriba. Detalle de letra capital

Abajo. Resultado positivo del test de batofenantrolina para tintas corrosivas
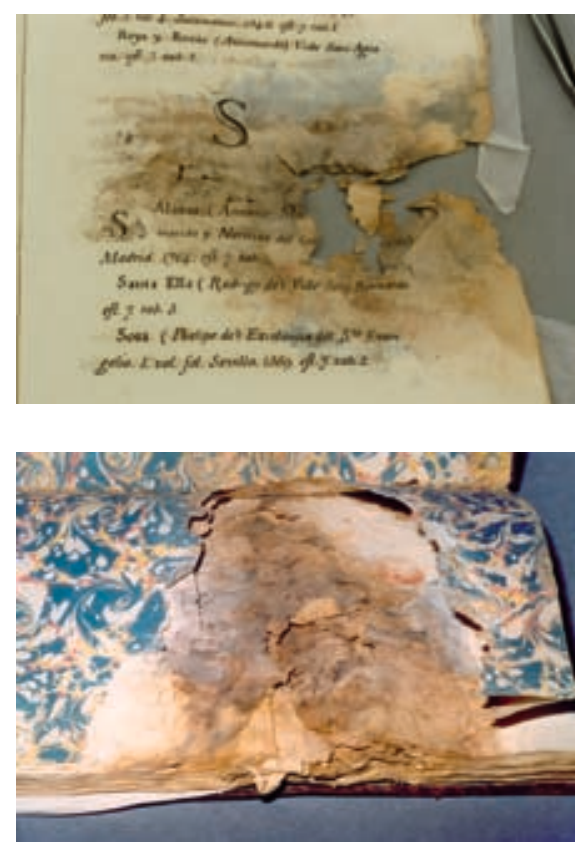

Arriba. Estado inicial de un grupo de hojas Abajo. Cuerpo del libro antes de la intervención a. Recortado de los fragmentos en porciones iguales en forma de cuadrados de $5 \mathrm{~mm}$ de lado colocándolos, para la medición, sobre vidrio de laboratorio.

b. Deposición de una gota de agua destilada para análisis -Mercksobre la muestra y medición del pH por contacto pasado un minuto, tomando la lectura tras estabilización de la medida.

El pH medio de las muestras fue 5.8.

\section{Pruebas sobre la piel de la cubierta}

Toma de muestras. De acuerdo con el método propuesto en Guidelines for the Conservation of Leather and Parchment Bookbindings de la Koninklijke Bibliotheek (SMIT; PORCK, 1997), se tomó una muestra de $100 \mathrm{mg}$ de fibras del reverso de la piel, a la que se añadieron $2 \mathrm{ml}$ de agua destilada para análisis, dejando macerar durante 1 hora para extracción de los productos solubles. En el extracto se realizaron las mediciones de $\mathrm{pH}$ y los análisis semicuantitativos de sulfatos y amonio.

Medición del pH de la piel. Los resultados de las mediciones, llevados a cabo con el mismo instrumental antes citado, sobre una gota del extracto depositada en un vidrio de laboratorio, dieron un pH medio de la piel de 5.98. Tras diluir la muestra 10 veces con agua destilada, el pH medio obtenido fue de 6.22 por lo que el pH diferencial es de 0.24 .

Determinación de sulfatos. En el extracto diluido 10 veces se realizó la determinación de sulfatos con el test colorimétrico Aquaquant 14423 (Merck). Realizados los cálculos para adecuar los resultados a la muestra sin diluir, resultó que la concentración aproximada de sulfatos en el extracto de $100 \mathrm{mg}$ de piel en $2 \mathrm{ml}$ de agua fue del $0.5 \%$.
Determinación de amonio. En otra parte del extracto diluido se realizó la determinación de amonio, con el test Microquant 14789 (Merck). Los resultados fueron imposibles de determinar debido a la coloración inicial del extracto.

Determinación de taninos. El pH obtenido en la piel resultó muy alto para tratarse de una piel de curtido vegetal, las cuales suelen tener un pH más ácido, del orden de 4. Para confirmar que se trata de un curtido vegetal se realizó el test de presencia de taninos (FREDERICKS, 1997) depositando una gota de disolución al 1\% de sulfato de hierro (II) en una zona oculta de la cubierta. La coloración oscura de la zona probada confirmó la presencia de taninos.

\section{Deterioro biológico}

\section{Cuerpo del libro}

La obra presenta un estado altamente deteriorado por microorganismos que impide claramente su uso debido a la extrema debilidad del soporte en las zonas degradadas. El foco principal se sitúa en la zona central de la superficie del cuerpo del libro en su límite delantero, afectando levemente a las primeras hojas -aproximadamente 1/3 del total-, las cuales pueden manipularse cuidadosamente, y gravemente a los 2/3 restantes del final, de forma que su manipulación no es posible sin provocar roturas y pérdidas de soporte en las zonas degradadas. Existen otros focos de infección, situados en el margen superior del libro, que afectan a las primeras en mayor grado y levemente a las últimas, no afectando este foco a las hojas centrales. El deterioro microbiológico, producido con toda seguridad por mojado continuado -gotera-, además de la pérdida de resistencia lleva asociada la presencia de suciedad libre entre las hojas, compuesta por restos de micelio y otras partículas, así como manchas en el papel. 


\section{Encuadernación}

La infección por microorganismos afecta de la misma forma a las guardas, hojas de respeto y tapas de cartón. También ha sido afectada la estructura de costura y cabezada de la zona superior del lomo, presentando el hilo de la costura y los restos de hilo de la cabezada -la cabezada en si se encuentra perdida- una debilidad acusada. La piel ha resistido bien el ataque microbiológico; la zona que sufrió el mojado no presenta signos aparentes de debilitamiento característico de este tipo de infección. Sin embargo sí se aprecian signos, en todo caso leves, de actividad de insectos con pérdidas puntuales de piel por esta causa.

\section{Deterioro químico}

\section{Cuerpo del libro}

A nivel químico lo más reseñable es lo concerniente a la tinta ferrogálica, que se encuentra en un estado de actividad oxidativa, visible por sus características aparentes -oscurecimiento de los trazos por el reverso del papel- y corroborada por el resultado positivo de la prueba de detección de iones ferrosos. No obstante, aún no se aprecian agrietamientos o pérdidas importantes de soporte en zonas densamente entintadas ${ }^{6}$.

Las mediciones de $\mathrm{pH}$ realizadas sobre fragmentos del soporte sin tinta no sugieren un deterioro químico importante por acidez del papel en general.

\section{Encuadernación}

En el deterioro químico de los elementos de la encuadernación se aprecia un relativo envejecimiento de los cordeles que conforman los nervios de la costura, algunos de los cuales se han seccionado en el doblez de la tapa. El resto de materiales presenta un grado de flexibilidad aceptable, incluyendo la piel de la cubierta. En este sentido, el pH medido en la piel es sorprendentemente alto para tratarse de un curtido vegetal. El contenido en sulfatos tampoco sugiere un envejecimiento químico llamativo. No obstante, el mojado sufrido por una parte de la piel de la cubierta provocó una contracción acusada y rigidez en esta zona.

\section{Deterioro físico}

\section{Cuerpo del libro}

El extremo debilitamiento provocado por la degradación microbiológica era causa para que, en cualquier tipo de manipulación -simplemente el cambiar de lugar al libro-, se produjera un deterioro físico en alguna medida. Parte del soporte se perdió por literal desintegración de la materia. Otras pérdidas del soporte se debieron a su manipulación.

\section{Encuadernación}

Guardas y hojas de respeto se encontraban con el soporte perdido en las zonas infectadas. La estructura de la costura se encontraba en buen estado, salvo en la cadeneta de cabeza donde la infección causó el debilitamiento de la zona con la pérdida de la cabezada superior, permaneciendo en buen estado la cabezada de pie. El cartón de ambas tapas se encontraba totalmente disgregado en las zonas que fueron infectadas. La piel de la cubierta presentaba algunos deterioros por rozamiento, con abrasiones de la flor y pequeñas pérdidas ocasionadas por insectos.

\section{DETERMINACIÓN DEL TRATAMIENTO}

\section{Factores a considerar}

El precario estado de conservación del libro impide su manipulación, incluso la mínima necesaria para su reproducción digital, sin la realización de intervenciones de consolidación sobre sus hojas. Por otra parte, el carácter único del objeto, por su condición de manuscrito y sus características intelectuales, al tratarse de una obra de referencia para la historia del centro depositario, sugieren la recuperación integral del objeto, no sólo de la información que contiene.

El principio de respeto a la integridad de la obra mediante la intervención mínima exige conservar sin modificación alguna la mayor parte de los elementos originales del objeto. Por ello, se contempló desde el principio la posibilidad de un tratamiento sin desmontaje de los cuadernos, con el fin de conservar la costura original, realizando las operaciones de limpieza y consolidación de las hojas con el libro montado. Otras circunstancias reforzaban esta decisión; el desmontaje podria ser necesario sólo en los siguientes casos:

- Para un tratamiento acuoso -lavado- de las hojas. Tratamiento no indicado por tratarse de tintas ferrogálicas en proceso de deterioro, presentando el tratamiento acuoso numerosos riesgos de efectos no deseados (NEEVEL; REIZLAND, 1997)

- Para un tratamiento mecanizado. Ni la reintegración mecánica, por los motivos aducidos para el tratamiento acuoso, ni la laminación mecánica son tratamientos indicados para obras de este tipo y con este tipo de deterioro.

- En el caso de suma degradación de la costura. En el caso que nos ocupa, la costura aún mantiene unidos los cuadernos. Sólo la parte de la cadeneta de cabeza ha sufrido deterioro biológico, pero el resto de la costura se encuentra en buenas condiciones, cumpliendo su función.

Por lo tanto se optó por conservar la costura, realizando las reparaciones hoja a hoja con el libro montado.

Sin embargo, el alto grado de deterioro y debilitamiento de las tapas de cartón aconsejaba claramente su sustitución por nuevas tapas de un cartón adecuado.

La consolidación de las zonas debilitadas por microorganismos debe contemplar el uso de un adhesivo y refuerzos de papel tisú. El adhesivo debe ser de naturaleza no acuosa con el fin de evitar la formación de cercos característicos de arrastre de los productos de degradación solubles. En un principio se pensó en Kluce ${ }^{\circledR} G$ en isopropanol al que se añadiría una pequeña cantidad de agua o 
almidón; posteriormente surgió la idea de utilizar una disolución en agua y alcohol de metilhidroxietilcelulosa -Tylose ${ }^{\circledR} \mathrm{MH} 300^{7}$. En las pruebas preliminares se experimentó con ambas posibilidades para determinar la más adecuada.

\section{Pruebas preliminares}

Las pruebas se dirigieron a determinar el método de desmontaje de los elementos de la encuadernación y a la determinación del adhesivo más apropiado para llevar a cabo las intervenciones de consolidación del papel.

\section{Desmontaje de guardas}

Con el fin de contemplar o no la intervención de un producto acuoso - p. ej. gel- para el desmontaje de las guardas, así como para su posible tratamiento posterior o no mediante lavado, se comprobó la resistencia al agua de los colores presentes en las guardas pintadas. Haciendo rodar una torunda de algodón ligeramente húmeda se apreció sensibilidad de la tinta ante la humedad, al quedar el algodón teñido con la tinta evaluada.

A continuación se probó a despegar en seco la guarda del cartón, con ayuda de espátulas, comprobándose que la adhesión había sido degradada en gran medida y estos métodos mecánicos eran suficiente para el despegado de guardas.

\section{Desmontaje de hojas de respeto}

Una vez despegadas las guardas, en el transcurso del tratamiento, quedaron a la vista las solapas de refuerzo, procedentes de las hojas de respeto, firmemente adheridas a las tapas sin posibilidad de despegado exclusivamente mecánico. Con el fin de determinar el método de desmontaje, se realizó una prueba con Laponite ${ }^{\circledR} \mathrm{RD}$ en gel acuoso al 10\%, aplicando el gel en una esquina de la solapa y dejando actuar. Se comprobó que el adhesivo se ablanda lo suficiente para el despegado seguro de la solapa de refuerzo.

\section{Desmontaje de la cubierta}

La cubierta se encontraba totalmente despegada de la tapa posterior por el deterioro alcanzado. En la zona de la tapa anterior se encontraba aún adherida. Se realizó una prueba de despegado mecánico, comprobándose que podia ser despegada, al igual que la guarda, de forma mecánica con la ayuda de espátulas, debido a la debilidad de la adhesión.

\section{Pruebas con adhesivos para la consolidación del papel}

Se hicieron pruebas preliminares de consolidación y adhesión del tisú de refuerzo sobre sendas hojas en blanco de la obra, con los siguientes adhesivos:

- Kluce ${ }^{\circledR} G$ (hidroxipropilcelulosa) en isopropanol al 3\% con adición de una pequeña cantidad -un 5\% v/v-de almidón de trigo preparado a $40 \mathrm{gr} / \mathrm{l}$.

- Tylose ${ }^{\circledR} \mathrm{MH} 300 \mathrm{P}$ (metilhidroxietilcelulosa) al 2.2\% en disolución de agua -15\%- e isopropanol -85\%.
Los resultados mostraron que ambos adhesivos ofrecian buenos resultados: no provocaban la aparición de cercos de humedad, secaban rápidamente, penetraban y consolidaban el papel debilitado, adhieriendo eficientemente el tisú de refuerzo y deformando mínimamente al papel tras el secado, deformación fácilmente corregible alisando con espátula termostática una vez seco el adhesivo. Finalmente, como veremos en el tratamiento propuesto, se optó por la MHEC por presentar una estabilidad contrastada, mientras que la HPC es menos segura en ese sentido (FELLER; WILT, 1990).

\section{Tratamiento propuesto}

Teniendo en cuenta todos los factores relativos al valor intrinseco de la obra, su estado de deterioro y los análisis previos y pruebas preliminares realizados, se determinó un tratamiento de restauración con las siguientes intervenciones:

- Limpieza superficial de la suciedad libre por aspiración en todas las fases del tratamiento de desmontaje y consolidación.

- Desmontaje en seco de las guardas de tapa, previa laminación de protección con tisú de las zonas debilitadas y anotación con grafito de su disposición.

- Desmontaje en seco de la cubierta de piel y de las tapas de cartón. - Desmontaje del conjunto formado por guardas y hojas de respeto, tanto anteriores como posteriores, descosiéndolas del cuerpo del libro para su tratamiento por separado.

- Consolidación de la cabezada y lomo, mediante aplicación de un adhesivo y un tisú de refuerzo, para evitar su deterioro durante el tratamiento de las hojas.

- Tratamiento de las hojas del cuerpo del libro, una a una, con las siguientes operaciones sistemáticas:

- Limpieza de la suciedad libre con aspirador y pinceles suaves.

- Anotación, con grafito, de paginación provisional, realizando durante el tratamiento el diagrama de cuadernos.

- Aplicación del adhesivo sobre la zona degradada, por el reverso, superponiendo posteriormente un tisú adecuado con la forma de la zona débil y volviendo a aplicar adhesivo sobre él para lograr su adhesión.

- Secado al aire de la zona intervenida con el adhesivo.

- Eliminación de las deformaciones causadas por el adhesivo, una vez seco éste -mediante alisado con espátula termostática a $110^{\circ} \mathrm{C}$, protegiendo con una lámina de Hollytex ${ }^{\circledR}$ entre espátula y papel.

- Consolidación de la zona degradada del lomo y margen de cabeza, reparando los pliegues rotos, una vez determinadas las correspondencias entre las hojas mediante tisú de refuerzo utilizando el mismo adhesivo.

- Reproducción digital del libro una vez consolidadas todas las hojas.

- Reintegración de las zonas de las hojas con pérdida del soporte original, mediante injertos con un papel japonés adecuado.

- Desacidificación en seco con un producto comercial, por nebulización, como método para estabilizar, en cierta medida, el deterioro producido por las tintas.

- Tratamiento de la hojas de respeto con las intervenciones siguientes: 


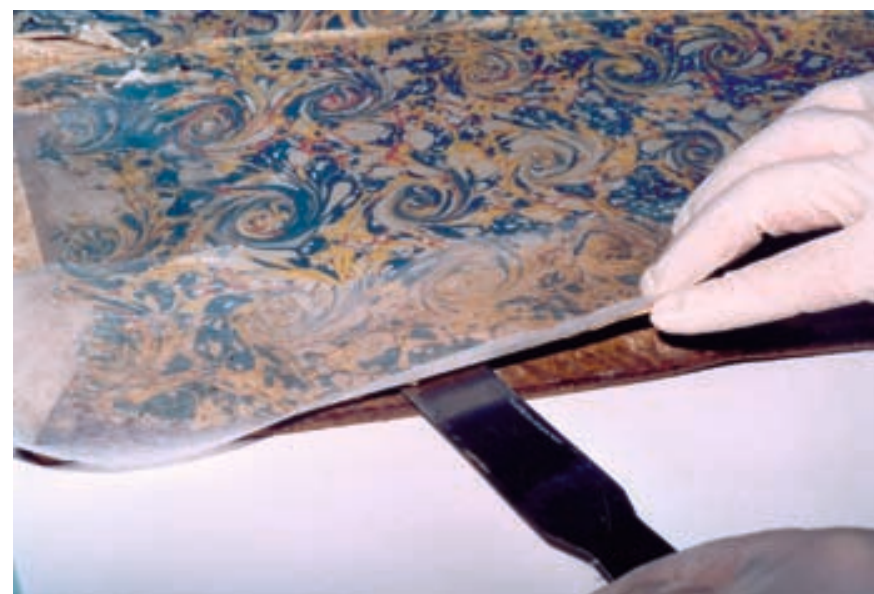

Despegado en seco de guardas previa protección de zonas degradadas

- Limpieza de la suciedad libre por aspiración.

- Lavado y reaprestado.

- Consolidación con papel tisú en las zonas degradadas y reintegración de zonas perdidas con injertos de papel japonés.

- Limpieza y consolidación de las guardas, incluyendo su laminación por el reverso y la reintegración del soporte perdido.

- Tratamiento de la cubierta de piel, incluyendo las intervenciones:

- Limpieza de restos de adhesivo y cartón, pegados por el reverso, por medios mecánicos y aspiración.

- Ligera limpieza superficial de la suciedad adherida, por el anverso, con algodón levemente humedecido en isopropanol.

- Estiramiento de la zona contraída mediante humectación y secado bajo tensión.

- Montaje, con los siguientes procesos:

- Cosido, sobre el cuerpo del libro, de las hojas de respeto y guardas en su disposición original.

- Enlomado y adecuación de los cajos.

- Cortado, ajustado y montaje de nuevas tapas de cartón adecuado.

- Adhesión de cubierta de refuerzo de papel japonés.

- Adhesión de la cubierta original y pegado de refuerzos y guardas.

\section{DESARROLLO DEL TRATAMIENTO}

\section{Desmontaje de guardas, hojas de respeto, cubierta y tapas}

\section{Limpieza por aspiración}

Se realizó una primera limpieza con aspirador de la suciedad libre acumulada en las guardas y en la superficie exterior del libro. Se utilizó un aspirador Museum VAC ${ }^{\circledR}$-Convac, Ltd.- con boquillas de pelo de cabra.

\section{Laminación de protección}

Las zonas debilitadas por microorganismos, tanto en las guardas como en las hojas de respeto, se laminaron provisionalmente para su protección durante el desmontaje. Se utilizó para ello tisú de fibras de manila de $9 \mathrm{gr} / \mathrm{m}^{2}$ sin dirección de fibra ${ }^{8}$, adherido con Kluce ${ }^{\circledR} \mathrm{G}$ en isopropanol al 1.5\%. Para ello se aplicó el adhesivo a través del tisú.

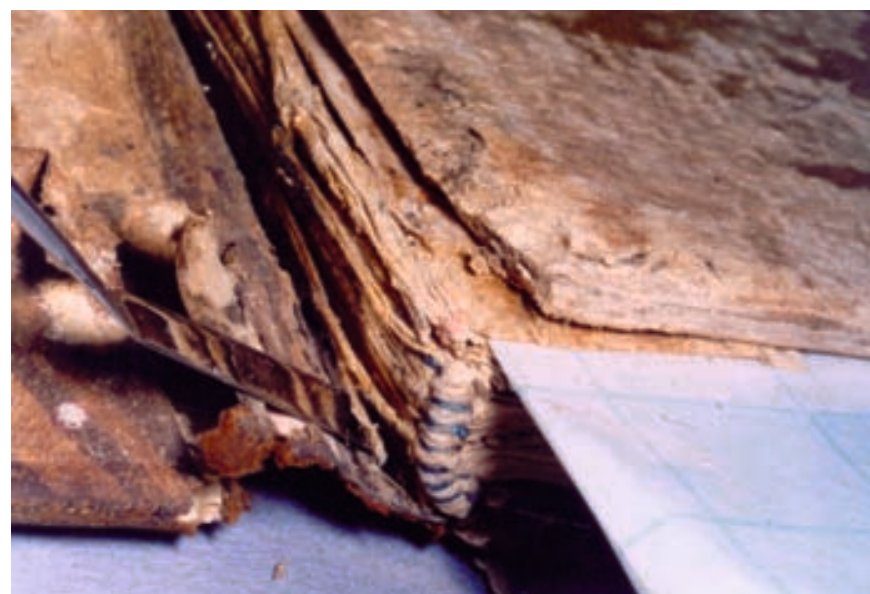

Desmontaje de la cubierta de piel, quedando a la vista la estructura de la cabezada

Despegado de guardas

Despegado de las guardas de tapa de forma mecánica, una vez seca la laminación anterior, con ayuda de espátulas metálicas. La debilidad del adhesivo permitió el despegado sin problemas de ambas guardas de tapa. Terminada la operación, se aspiró la cara interna de las guardas despegadas y la superficie del cartón de las contratapas.

\section{Despegado de solapas de refuerzo}

Tras las guardas, quedaron a la vista las solapas de refuerzo procedentes de las hojas de respeto sólidamente unidas a las tapas. Para su despegado se utilizó Laponite ${ }^{\circledR}$ RD en gel acuoso al 10\%. Se aplicó el gel con espátula sobre la superficie a despegar, dejando actuar durante aprox. 25 minutos para el reblandecimiento del adhesivo. Posteriormente se retiró el gel, procediendo al despegado de la solapa con ayuda de la espátula metálica y tirando suavemente de ella.

Desmontaje de la cubierta de piel

La cubierta se encontraba prácticamente despegada de las tapas debido al gran deterioro biológico de cartones y adhesivos, sólo la tapa anterior presentaba algunos puntos de adhesión con la cubierta en vueltas y planos, que pudieron soltarse de forma mecánica. Tras el desmontaje de la cubierta se limpió con aspirador el reverso de la misma.

\section{Desmontaje de tapas}

Las tapas se encontraban fijadas al cuerpo del libro por adhesión de los nervios sobre ella. Sólo algunos de ellos conservaban esta adhesión, siendo despegados de forma mecánica con la espátula metálica.

Descosido y desmontaje de guardas y hojas de respeto Seccionando el hilo de la costura se soltaron y desmontaron los conjuntos formados por las guardas y hojas de respeto. La adhesión provocada por el adhesivo del lomo era débil, pudiendo desmontarse tirando suavemente de las hojas.

Todos los elementos desmontados se conservaron por separado para su tratamiento y reutilización en el montaje salvo las tapas de cartón, que serán sustituidas. 


\section{Limpieza y consolidación del cuerpo del libro}

\section{Consolidación previa de cabezada, nervios y lomo}

Con el fin de evitar su deterioro físico durante las operaciones de consolidación de las hojas del libro, estos elementos fueron previamente consolidados mediante la aplicación de almidón de trigo y adhesión de tisú como refuerzo ${ }^{9}$ en la parte posterior de la cabezada y en los entrenervios.

\section{Intervenciones sobre las hojas}

Las siguientes operaciones se realizaron en cada una de las hojas del libro. Para aislar el resto de hojas del libro durante el tratamiento de cada folio se prepararon dos láminas de cartoncillo neutro a las que se adhirieron sendas hojas de papel siliconado. El alto grado de debilidad, sobre todo en las hojas centrales y finales -e primer tercio de las hojas no presentaron problemas en este sentido-, por la adhesión entre las hojas contiguas debido a los restos de microorganismos y al propio apresto del papel, así como por la presencia de múltiples dobleces y plegados en grupos de hojas, dificultó la operación de levantar las hojas para individuar su tratamiento, colocando bajo ellas la lámina aislante. En algunos casos se utilizaron hojas de poliéster ${ }^{10}$ cargadas de electricidad estática a ser frotadas con un papel: la lámina atrae electrostáticamente a las hojas, prestando un soporte adicional para el despegado entre si en las zonas más débiles. Una vez separadas, cada hoja fue tratada con las siguientes operaciones.

Foliado y recolección de fragmentos sueltos. La primera operación consistió en numerar consecutivamente con grafito el orden de los folios y recoger los eventuales fragmentos sueltos presentes en la superficie. Este proceso no fue previsto inicialmente ya que la presencia de gran cantidad de fragmentos sueltos entre las hojas no fue observada durante el examen previo por la imposibilidad de abrir el libro en el estado inicial. Además, durante la separación de las hojas, se desprendieron asimismo bastantes fragmentos. Esta circunstancia ocasionó la inclusión en el tratamiento de dos operaciones no incluidas en la propuesta de tratamiento: la recolección y conservación de los fragmentos, y la recolocación de éstos en sus lugares correspondientes una vez consolidadas las hojas. Los fragmentos fueron conservados entre dos láminas de Melinex ${ }^{\circledR}$ de 125 micras con uno de sus lados soldados entre sí, anotando sobre el plástico el número de hoja donde se recuperó el fragmento.

Alisado de pliegues. Las zonas degradadas, sobre todo en las hojas centrales, presentaban sus bordes con numerosos pliegues. La siguiente operación consistió en el desplegado de los bordes del papel, con la ayuda de espátula metálica, pinzas y alisando finalmente con espátula termostática a $110^{\circ} \mathrm{C}$.

Limpieza. Una vez extendida toda la hoja sobre la superficie del cartón aislante se realizó la limpieza de la suciedad libre por aspiración, por anverso y reverso de las hojas. En las zonas resistentes se utilizó boquilla de pelo de cabra en el tubo del aspirador; en las zonas debilitadas se removieron las partículas con pincel de pelo de marta, sujetando cerca la boquilla del aspirador para absorber el polvo removido. En las zonas extremadamente débiles no se practicó este tipo de limpieza.

Consolidación de las zonas debilitadas. Se realizó la consolidación del papel afectado por deterioro microbiológico mediante el adhesivo hidroalcoholico de MHEC" y la adhesión de tisú japonés de refuerzo ${ }^{12}$. El proceso de consolidación contó con las siguientes etapas:

- Recortado de la pieza del tisú con la forma de la zona degradada -y un margen adicional-. Para ello se calcó la zona perdida sobre la hoja con lápiz dejando un margen amplio, aplicando una línea de agua ${ }^{13}$ con pincel tras la línea calcada, lo que permitió rasgar el tisú por la línea húmeda. De esta forma quedaban los bordes desfibrados.

- La hoja a consolidar se colocó con su reverso visto sobre un soporte de Hollytex ${ }^{\circledR}$ y bajo éste un secante -la lámina de cartoncillo aislaba el resto de hojas-. Se aplicó el adhesivo sobre la zona a consolidar, superponiendo seguidamente el tisú y volviendo a aplicar adhesivo sobre éste. En las zonas extremadamente débiles se aplicó el adhesivo sólo a través del tisú.

- Secado al aire, tras el cual se alisó la deformación causada por el adhesivo con espátula termostática a una temperatura de $110^{\circ} \mathrm{C}$. Tras estas operaciones de consolidación, las hojas recuperaron una resistencia suficiente para su manipulación segura. En las zonas con el soporte perdido quedó visible el tisú de refuerzo, sobre el que podrán ser adheridos posteriormente los fragmentos sueltos o, en su caso, los injertos de papel japonés.

En la serie de la página 120 puede apreciarse el proceso completo de consolidación de una de las hojas:

Reparación de los pliegues afectados por biodeterioro

El segundo foco de biodeterioro de situaba en la zona superior del lomo. Como consecuencia, los pliegues de los cuadernos y el hilo de la costura estaban debilitados y con roturas. La consolidación de estas zonas se realizó durante el tratamiento de las hojas, tras determinar la disposición de cada cuaderno. Una vez consolidadas las hojas de un cuaderno completo se realizó la reparación del pliegue en cada bifolio del cuaderno, comenzando con el bifolio central. La reparación consistió esencialmente en la misma intervención realizada en las hojas, es decir, aplicación del mismo adhesivo y pegado de una tira de refuerzo de papel tisú de $8 \mathrm{gr} / \mathrm{m}^{2}$. El reforzamiento se realizó por la cara interna de cada pliegue, salvo en el bifolio exterior de cada cuaderno, en el que se adhirió un segundo tisú de refuerzo por la cara exterior.

\section{Recomposición de fragmentos}

Tras la consolidación del cuerpo del libro, se habian recogido y almacenado un gran número de fragmentos, algunos de ellos de tamaño considerable, y muchos otros pequeños. Se efectuó la colocación de estos fragmentos en su lugar, adhiriéndolos, con el mismo adhesivo utilizado en la consolidación, sobre el tisú de pro- 

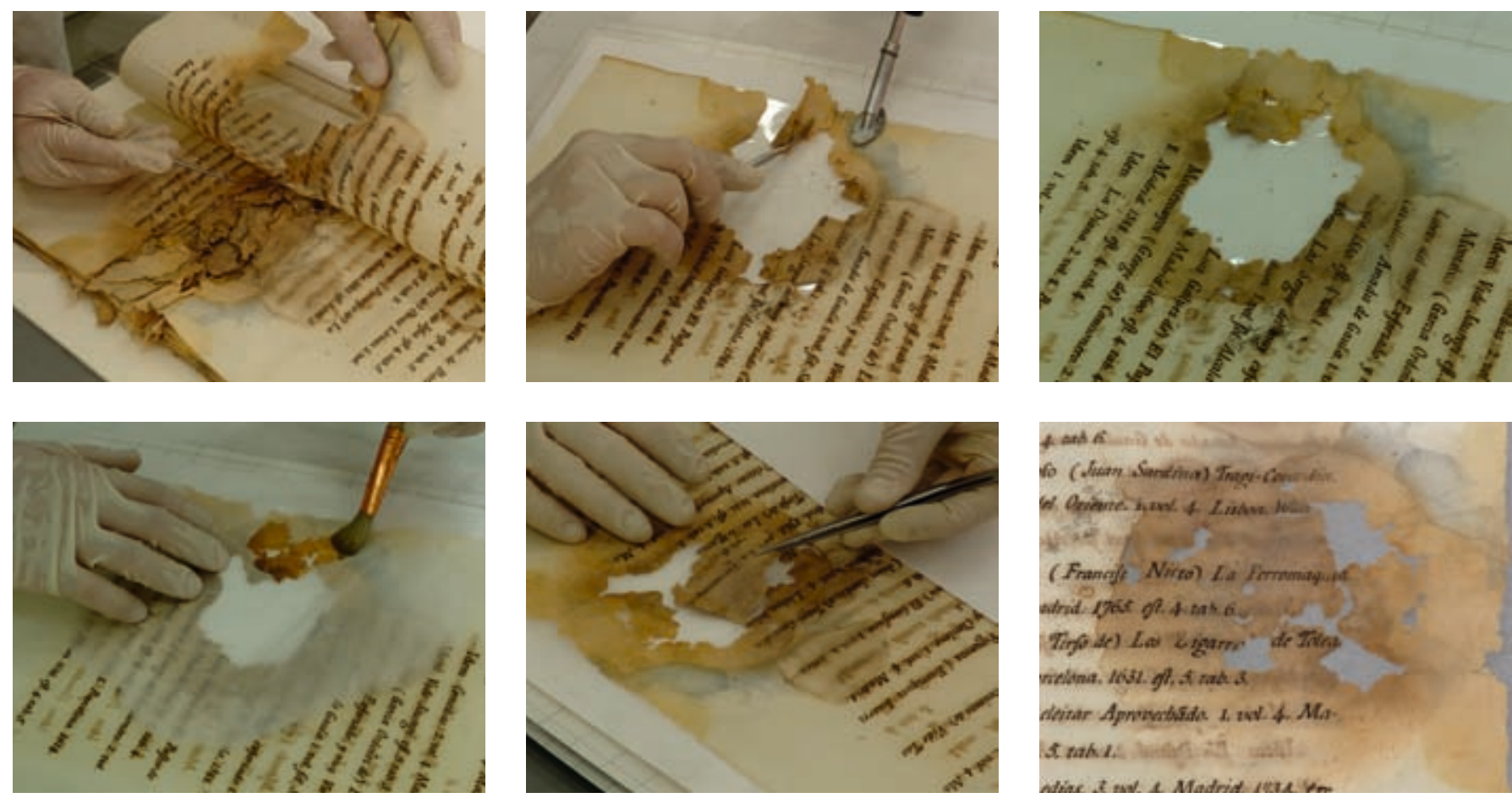

Proceso completo de consolidación de una hoja: individuación, alisado, reforzamiento con tisú y recomposición de fragmentos

tección. El hecho de tratarse de un catálogo de biblioteca facilitó la recomposición, ya que podian ser relacionados los datos escritos en los fragmentos, con búsquedas en los catálogos de fondo antiguo. En este sentido, fueron útiles, y disponibles en Internet, el Catálogo Colectivo del Patrimonio Bibliográfico Español, el de la Biblioteca Nacional de España y el de la British Library. Otros criterios para la recolocación de fragmentos fueron la forma de fragmento y hueco, la correspondencia entre la grafía de anverso y reverso, y la verjura del papel. Para el pegado correcto de fragmentos grandes se sujetaron en la posición correcta -lo cual se comprobaba con la ayuda de luz transmitida- con un vidrio en la mitad de su superficie, pegando la mitad libre del fragmento, para a continuación pegar la otra mitad. Se reubicaron la mayor parte de los fragmentos, salvo algunos de pequeño tamaño que fueron conservados en un montaje especial entre láminas de Melinex ${ }^{\circledR}$ de 125 micras, para su almacenamiento junto a la obra.

\section{Reproducción digital}

Una vez consolidadas y recompuestas todas las hojas llegó el momento apropiado para realizar una reproducción digital del texto, ya que una vez montada la encuadernación original el libro será más sensible al deterioro en la manipulación.

\section{Reintegración del soporte perdido}

Para dotar de mayor consistencia las hojas con amplias zonas perdidas, se realizaron injertos tipo "de alfiler" por el anverso de las hojas, con papel japonés Kawashi -NAO- de $35 \mathrm{gr} / \mathrm{m}^{2}$ color crema claro. Las pequeñas pérdidas no se reintegraron, permaneciendo consolidadas con el tisú de refuerzo. Se determinó la no realización de estos pequeños injertos ya que el coste de tiempo requerido no se corresponde con un impacto positivo claro en la estabilidad me- cánica del soporte, mientras que la reintegración de las pérdidas de mayor tamaño sí contribuyen a una consolidación clara de las hojas, permitiendo una manipulación más segura. La técnica para la realización de los injertos contó con las siguientes operaciones:

- Calcado de la zona perdida sobre el papel japonés utilizando una hoja de luz, dejando un borde adicional de $3 \mathrm{~mm}$ aproximadamente. - Horadado del perímetro del injerto. La línea de perforaciones se hizo a 1-2 mm de la línea dibujada hacia el interior del injerto.

- Rasgado del injerto por la línea de perforaciones, dejando un borde fibroso.

- Para el pegado del injerto, una vez situados los soportes de protección bajo la hoja -Hollytex ${ }^{\circledR}$, secante y cartoncillo aislante- se colocó el injerto en seco, en la posición correcta, con ayuda de la hoja de luz, sujetándolo en esta posición superponiendo una pieza de vidrio en la mitad de la superficie. A continuación se pegó la mitad no sujeta por el vidrio, aplicando el adhesivo -el mismo usado para la consolidación- bajo el injerto y sobre el tisú de refuerzo para, seguidamente, tras levantar el vidrio, pegar la mitad restante. Para completar el pegado se aplicó adhesivo por el reverso a través del tisú de refuerzo y nuevamente por el anverso en toda la superficie del injerto, del centro hacia fuera para adherir las fibras de los bordes.

- El secado se realizó al aire, alisando una vez seco mediante espátula caliente a $110^{\circ} \mathrm{C}$.

\section{Estabilización química y acabado del cuerpo del libro}

\section{Desacidificación no acuosa por nebulización}

Si bien actualmente no está definitivamente establecido un tratamiento en seco -como por nebulización- para la estabilización de tintas ferrogálicas en proceso de oxidación ${ }^{14}$, si se ha demos- 

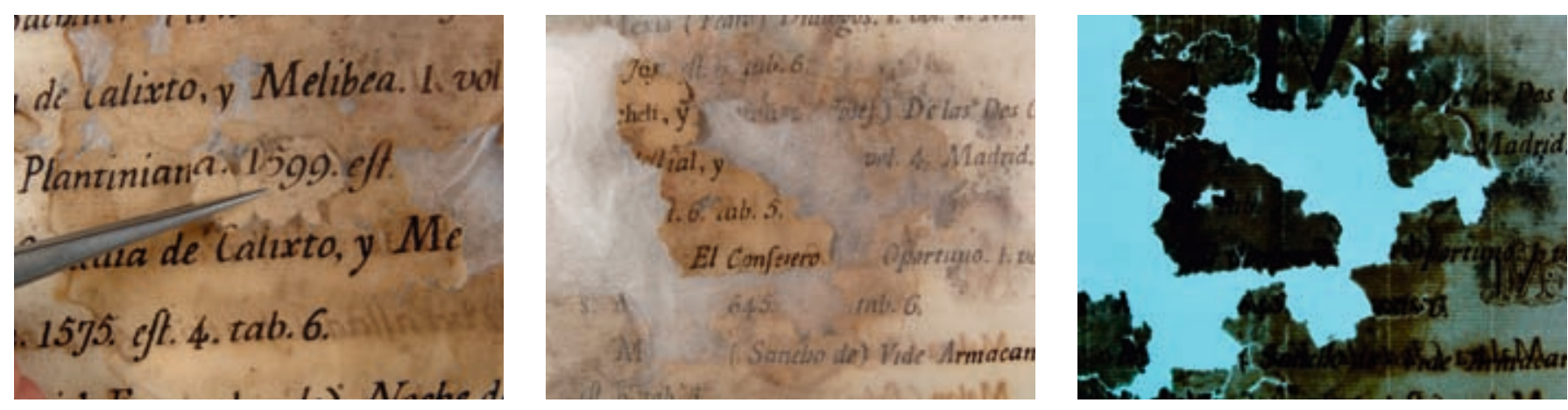

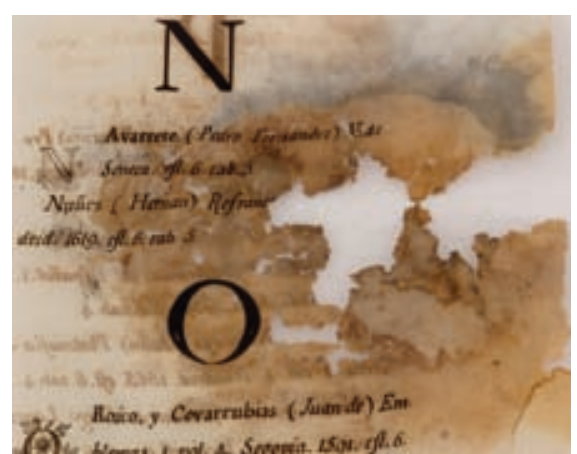

Localización de la ubicación de pequeños fragmentos (arriba)

Detalle de pérdidas de soporte (abajo)

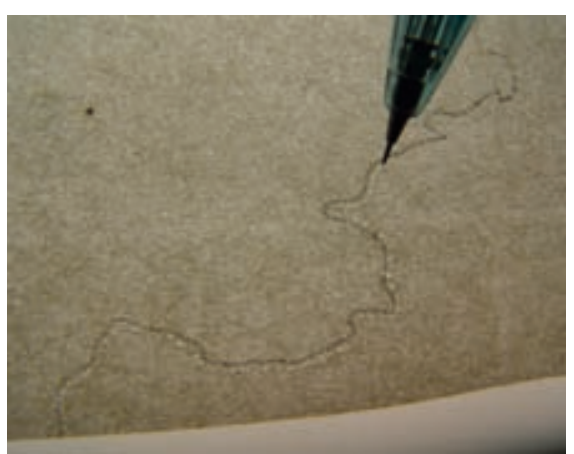

Localización de fragmentos por el texto (arriba) Modo de horadar el papel japonés para el recortado de injertos (abajo)

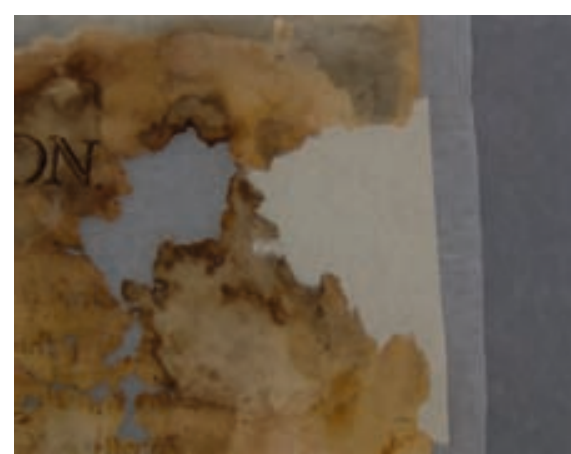

Localización de fragmentos por la verjura del papel (arriba)

Detalle de injerto finalizado (abajo) trado claramente que la reserva alcalina proporcionada por un tratamiento de desacidificación en seco, estabiliza y retrasa en cierta medida el deterioro químico producido por la tinta, siendo más efectivos, en este sentido, los productos en disolución que en suspensión de partículas (KOLAR, 2004). Por ello, y aunque el papel presenta un $\mathrm{pH}$ aceptable, se determinó la aplicación de un tratamiento no acuoso, en disolución, para la dotación de reserva alcalina, optándose por el producto CSC Booksaver ${ }^{\circledR}$-de Conservación de Sustratos Celulósicos, S. L.- que fue aplicado por nebulización hoja por hoja.

\section{Acabado}

Como últimas operaciones en el cuerpo del libro se recortaron los márgenes sobrantes de los soportes de refuerzo -tisú y papel japonés de injerto-. El recortado se efectuó trazando la línea de corte con grafito y posterior cortado con bisturí a mano alzada.

Intervenciones sobre guardas, hojas de respeto y cubierta Antes de proceder al montaje definitivo se realizaron las intervenciones de limpieza y consolidación sobre estos elementos de la encuadernación.

\section{Hojas de respeto}

Ambas hojas de respeto se trataron simultáneamente con las siguientes intervenciones:

- Lavado por flotación con agua desionizada a la que se añadió solución saturada de hidróxido cálcico hasta pH del baño de 9.5 . Previamente a su introducción en el baño las hojas fueron humectadas por nebulización de agua y etanol 1:1. Se realizaron 3 baños de 15 minutos cada uno.

- Durante el primer lavado se despegó el tisú de la laminación de protección y se limpiaron los restos de adhesivo de la zona del pliegue y la solapa de refuerzo, frotando suavemente con brocha japonesa de pelo suave.

- Reaprestado en baño de disolución de Tylose ${ }^{\circledR M H 300 P}$ al 0.2\% en agua.

- Secado al aire entre láminas de GoreTex ${ }^{\circledR}$ para procurar un secado suave.

- Consolidación del soporte en las zonas biodegradadas de la misma forma llevada a cabo en las hojas de la obra -adhesión de tisú con adhesivo hidroalcohólico-.

- Reforzamiento de las solapas que irán adheridas a las tapas en el montaje, mediante pegado en toda la superficie de papel japonés de $35 \mathrm{gr} / \mathrm{m}^{2}$, incluyendo una pestaña de $1 \mathrm{~cm}$ hacia el interior de las hojas de respeto -reforzando el pliegue-. La adhesión se realizó con almidón de trigo -40 gr/l-, sobre la mesa de succión.

- Reintegración del soporte perdido con injertos de papel japonés blanco de $35 \mathrm{gr} / \mathrm{m}^{2}$ realizados con la misma técnica y adhesivo utilizados en la reintegración de las hojas del cuerpo del libro.

\section{Guardas}

- Humectación entre secantes húmedos y láminas de GoreTex ${ }^{\circledR}$. Para ello se introdujeron las guardas en un "sándwich" compuesto, por este orden (del interior al exterior), de: láminas de Hollytex ${ }^{\circledR}$, láminas de GoreTex ${ }^{\circledR}$, secantes húmedos, envolviendo finalmente el conjunto en polietileno. Durante la humectación se realizó el despegado de la laminación de protección aplicando isopropanol sobre el tisú para la disolución del adhesivo -Klucel-.

- Colocación de las guardas humectadas en la mesa de succión, donde se realizó una laminación por el reverso, utilizando como refuerzo papel tisú de fibras de manila de $9 \mathrm{gr} / \mathrm{m}^{2}$ adherido con la preparación de MHEC en agua y alcohol isopropilico utilizada en 
otras fases. La guardas laminadas fueron cubiertas, sobre la mesa de succión, con Hollytex ${ }^{\circledR}$ y un papel de filtro hasta secado completo. - Reintegración de las zonas perdidas con injertos de papel japonés Kawashi de $35 \mathrm{gr} / \mathrm{m}^{2}$ crema, con la misma técnica y adhesivo que en las hojas de la obra.

\section{Cubierta}

Las intervenciones sobre la cubierta, previas al montaje fueron: - Limpieza por el reverso de restos de adhesivos y cartón, por medios mecánicos, utilizando espátulas y bisturí.

- Limpieza por el anverso de la suciedad adherida mediante frotación con algodón levemente impregnado en isopropanol.

- Humectación local de la zona contraida mediante secantes húmedos recortados con la forma de la zona a humectar, interponiendo láminas de GoreTex ${ }^{\circledR}$.

- Estiramiento de la piel contraída. Para ello se cortó un cartón neutro del tamaño de la tapa, estirando con cuidado la piel y sujetando las vueltas con pinzas hasta secado completo.

\section{Montaje}

Una vez terminadas las intervenciones sobre el cuerpo del libro y los elementos de la encuadernación, el proceso final consistió en el montaje de la encuadernación, intentando no alterar las características originales de la misma. El montaje contó con las siguientes etapas:

\section{Cosido de guardas y hojas de respeto}

Cada conjunto formado por guardas y hojas de respeto se cosió en su disposición sobre los nervios originales, utilizando hilo de lino Barbour $n^{\circ} 25$. Para conseguir un fijado correcto del nuevo hilo, se introdujo en los dos cuadernos anteriores, realizando una nueva costura paralela a la original, cosiendo finalmente guardas y hoja.

\section{Operaciones sobre el lomo}

Con el libro introducido en la prensa de cajos se realizaron las operaciones siguientes:

- Aplicación de almidón de trigo sobre todo el lomo, adhiriendo un tisú de manila de $9 \mathrm{gr} / \mathrm{m}^{2}$.

- Una vez seca esta primera capa se aplicó una capa de mezcla 1:1 de adhesivo EVA -Evacón ${ }^{\circledR}$ - y almidón de trigo para formar una película flexible que permita modelar el cajo.

- Secada la capa anterior, marcado de cajos con golpes suaves de martillo.

- Enlomado con una pieza de papel japonés blanco de $35 \mathrm{gr} / \mathrm{m}^{2}$, al que se practicaron ranuras para salvar los nervios. La pieza contaba con solapas utilizadas posteriormente para reforzar la unión de las tapas. El pegado se hizo con almidón de trigo. En la zona del lomo afectada por biodeterioro, se adhirió un refuerzo adicional.

\section{Preparación y fijado de nuevas tapas}

- Cortado de las nuevas tapas tomando como referencia las antiguas y el tamaño del cuerpo del libro. El cartón usado fue Canson
Museum ${ }^{\circledR}$ de 3000 micras de grosor $-3 \mathrm{~mm}$ - aproximadamente el mismo de las tapas originales.

- Cortado de la gracia en las tapas en forma similar a las presentes en las tapas originales. Todas las aristas del cartón fueron ligeramente redondeadas mediante lijado.

- Fijado de las tapas en su posición correcta mediante el pegado de los nervios en su disposición original, adhiriendo asimismo la solapa de refuerzo del enlomado sobre el cartón de las tapas. Ambas adhesiones se realizaron con almidón.

\section{Adhesión de cubierta de papel japonés}

Tras realizar una protección del cuerpo del libro mediante envoltura en papel siliconado, se cubrió el libro completamente con papel japonés Tosa Seicho Shi -NAO- de $69 \mathrm{gr} / \mathrm{m}^{2}$, adhiriendo esta cubierta con almidón de trigo. La cubierta de papel japonés reforzará mecánicamente a la encuadernación y prevendrá la rotura de la cubierta original durante la manipulación del libro. El papel japonés quedará a la vista en las pequeñas zonas perdidas de la cubierta de piel.

\section{Montaje de la cubierta original}

Una vez seca la cubierta de papel japonés se sobrepuso la cubierta original sobre la estructura del libro con el fin de comprobar su ajuste sobre la estructura. Como ya se advirtió al cortar las tapas, la piel de la cubierta se encontraba encogida y no ajustaba al tamaño del libro. Esta circunstancia obligaba al uso de humedad en el adhesivo con el fin de que la piel dilatara lo suficiente para su montaje. Dada la buena condición de la piel, tanto aparente como en sus valores de $\mathrm{pH}$, la intervención de humedad podría ser tomada en consideración. Por ello, para lograr un ajuste perfecto de la cubierta sobre el libro, se determinó el uso de almidón de trigo, humectando previamente la piel entre secantes húmedos y láminas de GoreTex ${ }^{\circledR}$, para evitar una penetración excesiva del adhesivo al ser aplicado. Por lo tanto, las operaciones del montaje fueron:

Humectación de la cubierta entre secantes húmedos y láminas de GoreTex ${ }^{\circledR}$ durante 20 minutos aproximadamente.

Aplicación de almidón de trigo consistente sobre el reverso de la cubierta.

Se cubrió el libro con la cubierta empastada, adhiriendo en primer lugar el lomo, en su posición correcta, posteriormente ambos planos, estirando la piel hasta el ajuste de los cantos originales con los cantos del cartón de las tapas y, finalmente, adhiriendo las vueltas de la cubierta.

Se colocaron suplementos en el cajo interior y se mantuvo el libro cerrado, con peso, hasta secado completo de la cubierta (2 días).

Una vez seca la cubierta, se comprobó que el uso de almidón para la adhesión había provocado la aparición de manchas diversas sobre la piel aunque, en apariencia, no se produjo un endurecimiento de la misma. 

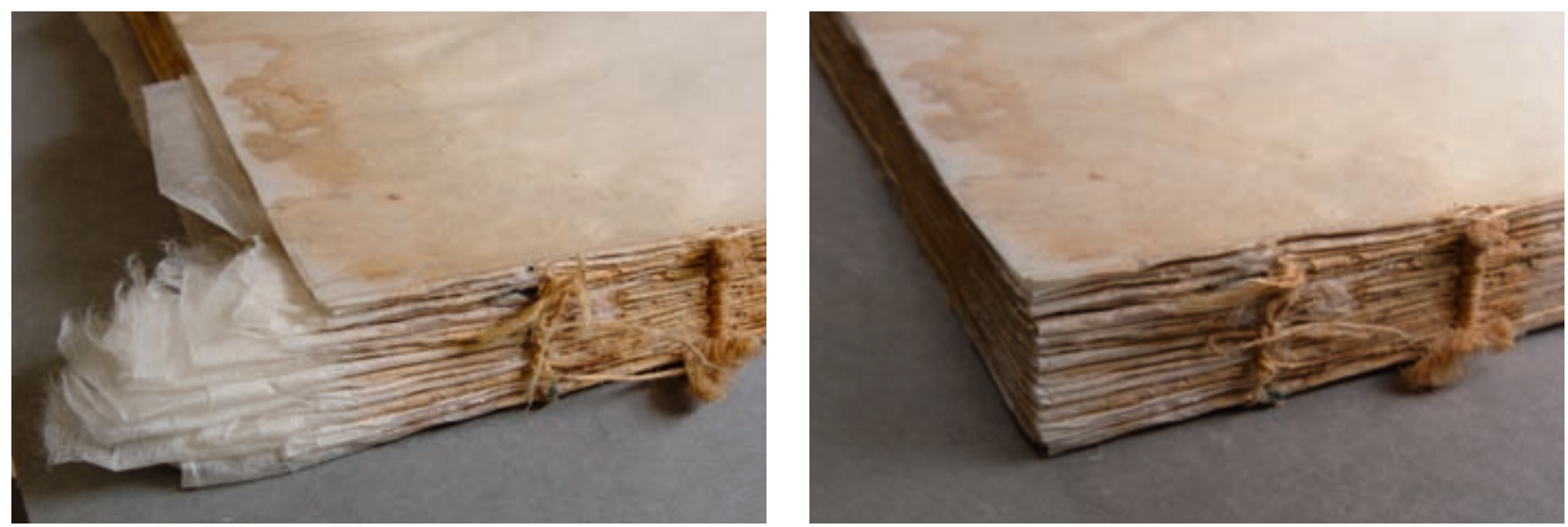

Recorte del papel de refuerzo sobrante

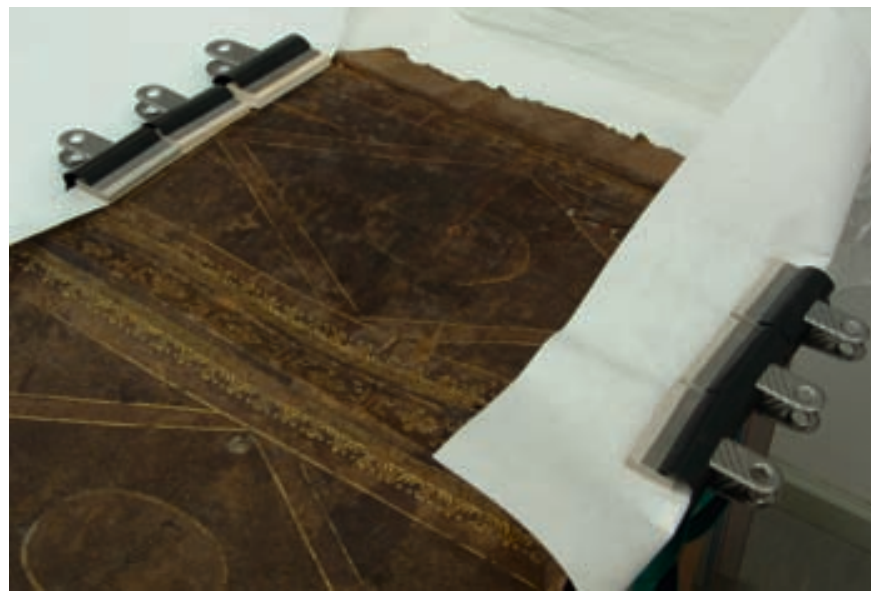

Estiramiento de la piel de cubierta

Recorte del papel de refuerzo sobrante

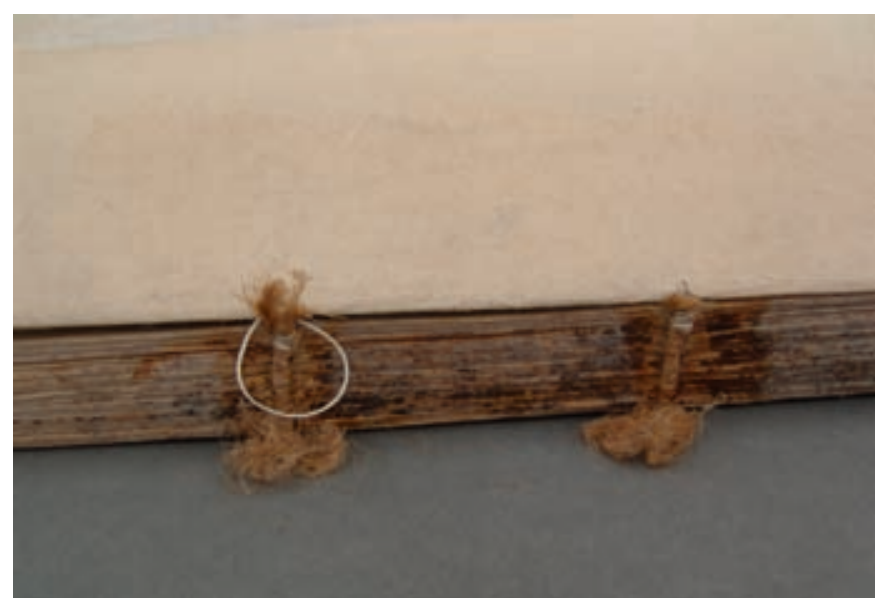

Detalle del cosido de los elementos desmontados

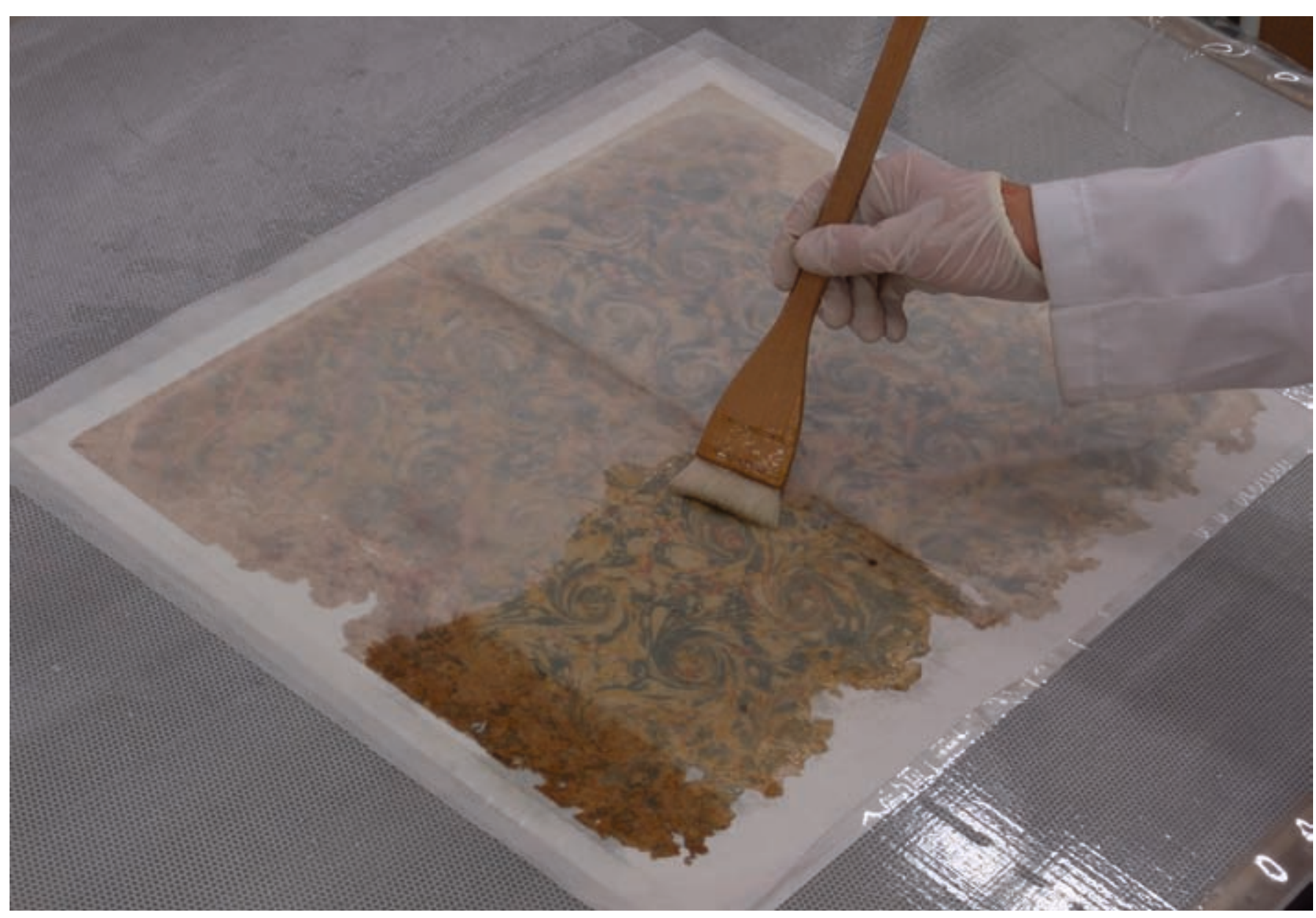




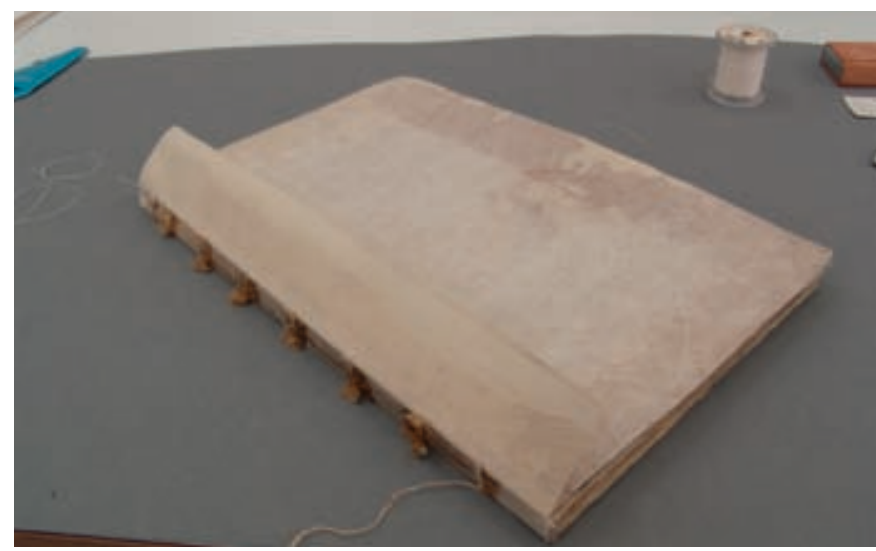

Aspecto final del cuerpo del libro con guardas y hojas de cortesía ya montadas

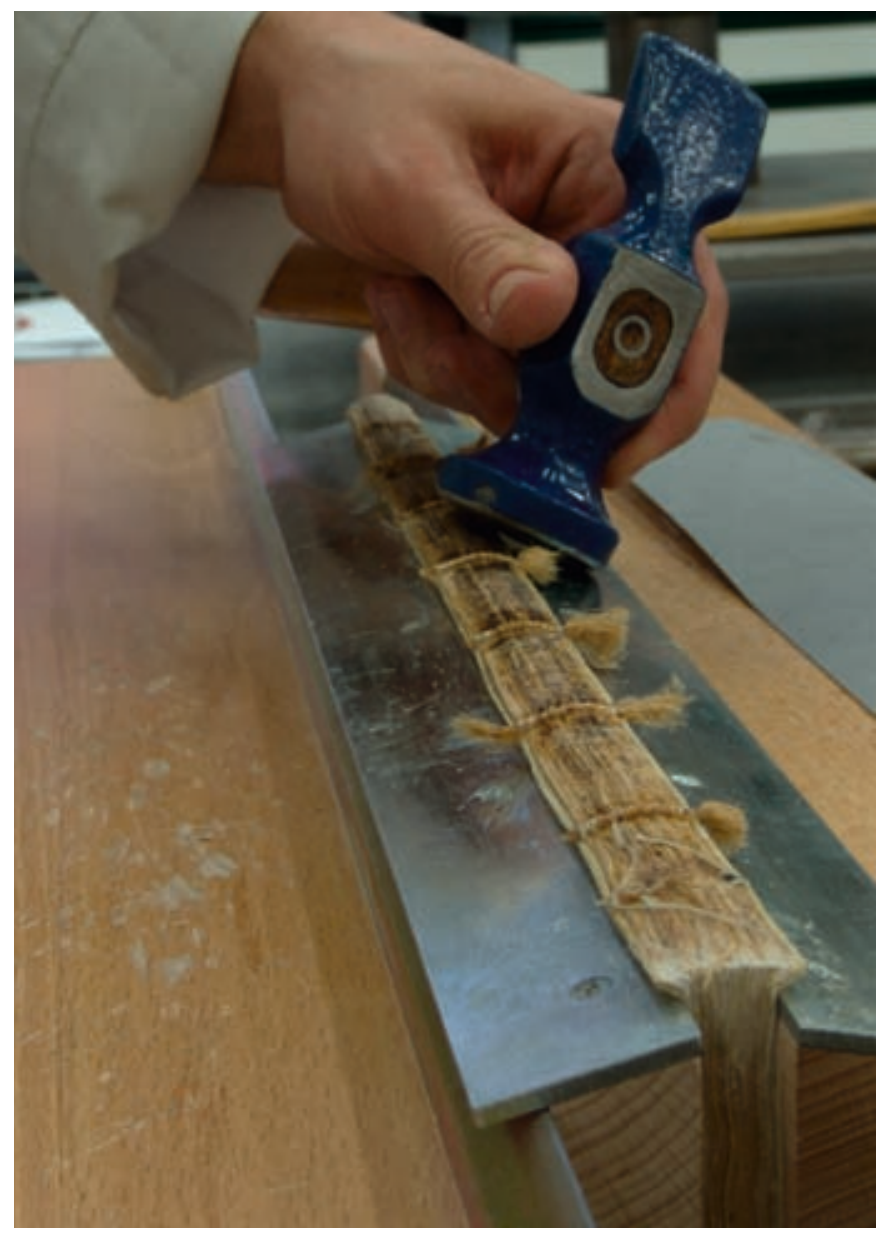

Marcado de cajos en la prensa

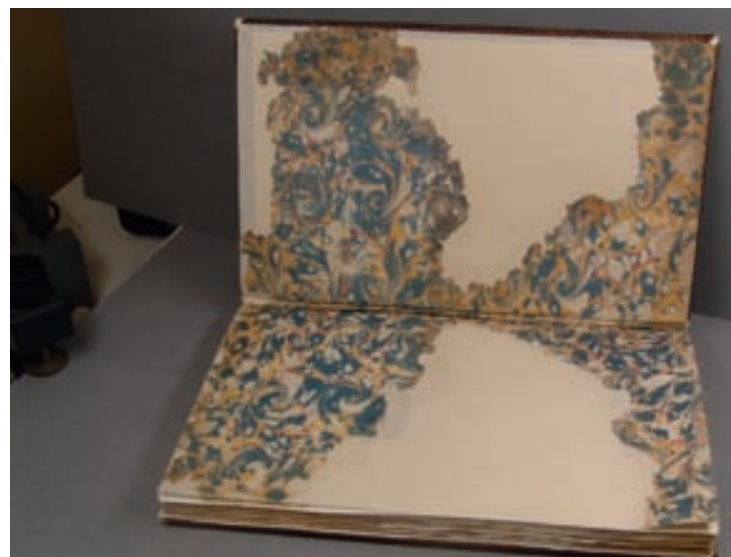

Aspecto de la obra tras la intervención

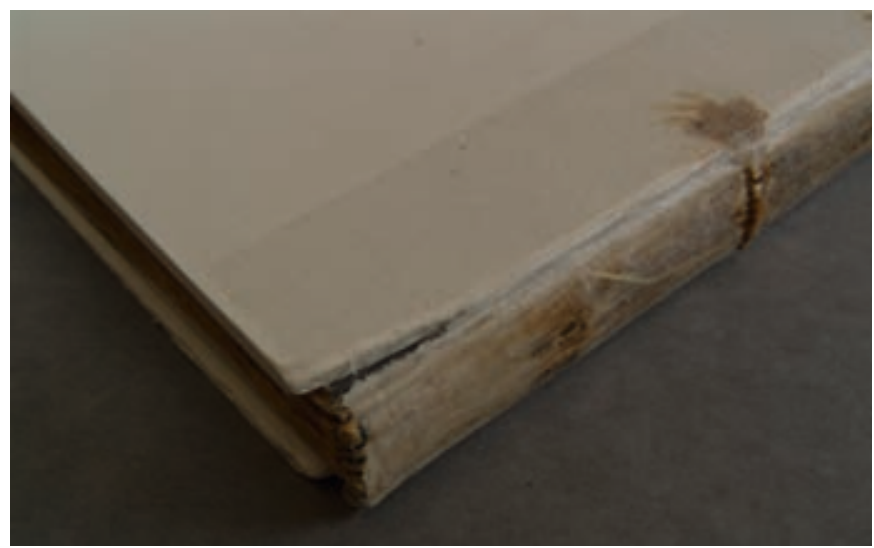

Detalle del cuerpo del libro con las nuevas tapas incorporadas

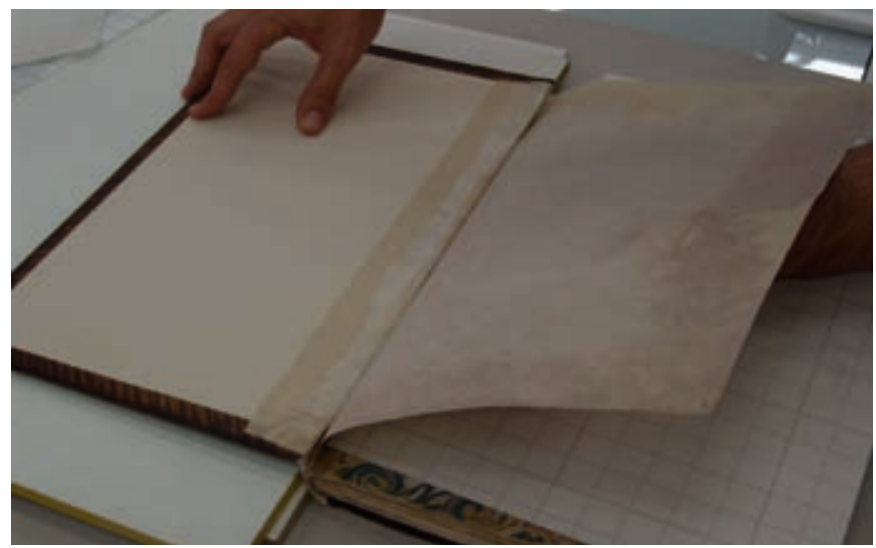

Proceso de adhesión de solapas de refuerzo y una de las guardas sobre la contratapa

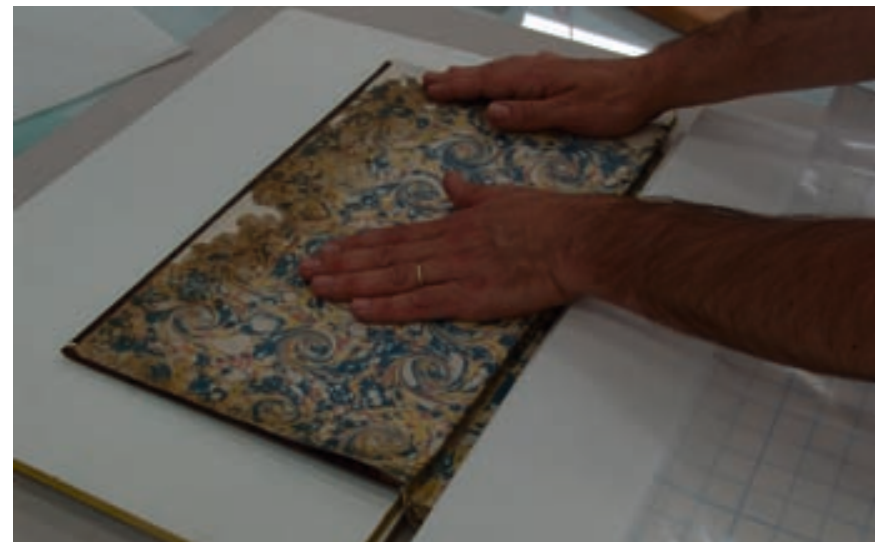

Proceso de adhesión de solapas de refuerzo y una de las guardas sobre la contratapa

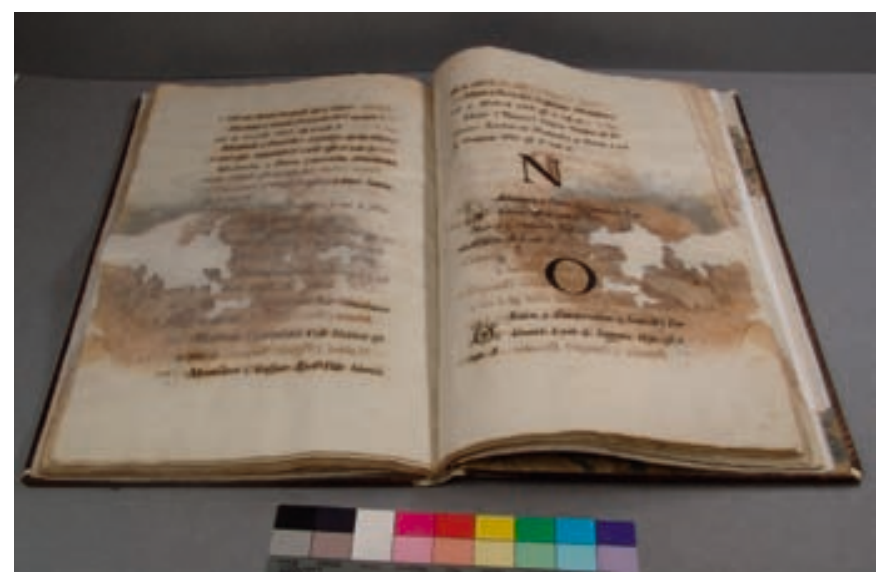

Aspecto de la obra tras la intervención 
Pegado de papel de tiro

Para contrarrestar la tensión que provocaba la piel, alabeando las tapas, se adhirieron papeles de tiro sobre ambas contratapas. Se utilizó papel manual verjurado Moulin du Verger de $90 \mathrm{gr} / \mathrm{m}^{2}$, adherido con almidón de trigo. Tras un primer periodo con el libro abierto -de unos 30 minutos- para forzar el secado. Posteriormente se mantuvo cerrado y con peso hasta secado total, corrigiéndose el alabeamiento.

\section{Adhesión de refuerzos y guardas}

Las solapas de refuerzo fueron adheridas con almidón de trigo, ciñendo el papel perfectamente a la forma del cajo. Se mantuvo la tapa abierta hasta secado parcial del almidón, cerrando el libro posteriormente y manteniendo con peso hasta secado total.

Para el pagado de las guardas de tapa se evaluó el uso del adhesivo hidroalcohólico de MHEC, para evitar, por un lado, la dilatación excesiva de la guarda, que dificultaria la adhesión correcta, y por otro lado la deslaminación y el desplazamiento de los injertos. Sin embargo este adhesivo no permitiria un ceñido correcto en la zona del cajo. Por ello se optó por un pegado en dos fases:

Pegado de la zona del cajo con adhesivo acrílico de carácter mordiente, optando por una mezcla a partes iguales de Lascaux 360HV y 498HV. Se aplicó el adhesivo en la zona del cajo (en el libro) ciñendo a continuación la guarda para su adhesión en esta zona.

Pegado de la superficie restante con el mismo adhesivo hidroalcohólico de MHEC, utilizado en otras fases del tratamiento.

Las guardas volantes se adhirieron a las hojas de respeto correspondientes con el mismo adhesivo anterior, aplicándose sólo en el margen de los cortes.

\section{Nota:}

Todas las imágenes incluidas en el artículo son de su autor, Javier Tacón Clavaín

\section{BIBLIOGRAFÍA}

BURGALETA, M.; DÍAZ, L. (2006) Restauración del Suplemento al Índice General de la Libreria de la Condesa de Campo Alange. Pecia Complutense [en línea], Año 3, no 4, enero de 2006. ISSN 1698-272X. Publicado en: www.ucm.es/BUCM/foa/pecia/num4/Articulos/0403.htm [1/8/2008]

FELLER, R. L.; WILT, M. (1990) Evaluation of Cellulose Ethers for Conservation [en linea]. The Getty Conservation Institute. Research in Conservation nº 3. 1990. Disponible en: www.getty.edu/conservation/publications/pdf_publications/ethers. $\operatorname{pdf}[1 / 7 / 2008]$

FREDERICKS, M. (1997) Progress in leather conservation, University of Texas, Austin. March 12-14, 1997. Conference Review. WAAC Newsletter [en línea]. Vol. 19(2) May 1997. Disponible en: palimpsest.stanford.edu/waac/wn/wn19/wn192/wn19-209.html [1/2/2007]

KOLAR, J. (2004) InkCor project - stabilisation of iron gall ink containing paper. En: KOLAR, J.; STRILC, M. Y HAVERMANS, J. (Eds.) Proceedings of the International Conference Durability of Paper and Writing. November 16-19, 2004, Ljubljana, Slovenia. - Ljubljana: National and University Library, 2004 ISBN. 961-6162-98-5. pp. $9-10$
NEEVEL, J. Y REIZLAND, B. (1997) Ink corrosion project at the NICH- a review. Abbey Newsletter, Vol. 21, 1997. pp 88-92

SANTOS, A. (2004) Un centro al servicio de la investigación y la difusión del patrimonio bibliográfico: La Biblioteca Histórica de la Universidad Complutense de Madrid. Pecia Complutense [en línea], año 1, n¹, junio de 2004. ISSN 1698-272X. Publicado en: www.ucm.es/BUCM/foa/pecia/num1/index01.htm [20/7/2008]

SMIT, W. J. T.; PORCK, H. J. (Eds.) (1997) Guidelines for the Conservation of Leather and Parchment Bookbindings [en línea]. (Edición traducida y revisada de: Richtlijnen voor de conservering van leren en perkamenten boekbanden). Den Haag : Koninklijke Bibliotheek; Amsterdam: Centraal Laboratorium voor Onderzoek van Voorwerpen van Kunst en Wetenschap, 1997, 64 p. Disponible en: www. kb.nl/cons/leather/index-en.html [21/8/2008]]

\section{NOTAS}

${ }^{1}$ Gran parte de los datos de la identificación intelectual de la obra proceden de comunicaciones personales de Ana Santos, entonces directora de la Biblioteca Histórica de la UCM, y de su artículo no publicado: El inventario de la Biblioteca de la Condesa de Campo Alange: un importante donativo para la Biblioteca Histórica.

${ }^{2}$ La obra quedó depositada con la signatura BH MSS 1096.

${ }^{3}$ En el s. XIX Bartolomé J. Gallardo resumió parte del inventario en un documento (depositado en la Biblioteca Menéndez Pelayo) titulado Índice de la Librería de la Condesa de Campo de Alange, año de 1779. Extracto.

${ }^{4}$ Algunas de las características en adelante descritas no se apreciaron en el examen previo pero se advirtieron durante el tratamiento al desmontar los elementos de la encuadernación.

5 J. Neevel, en el Netherlands Institute for Cultural Heritage, ha desarrollado tiras indicadoras con este compuesto, especialmente diseñadas para su uso sobre documentos, sin peligro de difusión de colorantes hacia el papel. Son comercializadas por Preservation Equipment Ltd. bajo el nombre de Iron Gall Ink Test Paper.

6 Para mayor información acerca del deterioro por tintas corrosivas véase: Ink Corrosion Website. Publicado en: www.knaw.nl/ECPA/ink/ [1/7/2008].

${ }^{7}$ La forma de preparación del adhesivo procede de una comunicación personal de Arsenio Sánchez en 2004.

8 -Spider's Wet Strength Tissue- (Conservation by Design, Ltd.).

${ }^{9}$ Se trata del mismo utilizado para las laminaciones de protección.

${ }^{10}$ Melinex ${ }^{\circledR}$-Poli (tereftalato de etileno)-.

11 Tylose MH 300P al 2,2\% en agua destilada (15\%) e isopropanol (85\%).

12 El tisú utilizado fue NAO kozo RK1 de $8 \mathrm{gr} / \mathrm{m}^{2}$.

13 Se añadió al agua una pequeña cantidad de adhesivo (MHEC) para disminuir la difusión del trazo líquido por capilaridad.

${ }^{14}$ Aunque existen investigaciones prometedoras en este sentido, en el marco del proyecto InkCor: www.infosrvr.nuk.uni-lj.si/jana/Inkcor/index.Htm [1/2/2007]. Véase también: MALESIC, J. y col. (2005) The use of halides for stabilisation of iron gall ink containing paper -the pronounced effect of cation. E-Preservation Science, 2005, 2, pp. 13-18. 